\title{
25 Research Square \\ Obstetric Fistula: a retrospective study of 413 cases in Haut-Katanga Province, Democratic Republic of Congo
}

Joseph B. Nsambi

Universite de Lubumbashi

Olivier Mukuku ( $\boldsymbol{D}$ oliviermukuku@yahoo.fr )

Institut Supérieur des Techniques Médicales de Lubumbashi https://orcid.org/0000-0001-6902-7023

Prosper L. Kakudji

Universite de Lubumbashi Faculte de Medecine

Robert Andrianne

Centre hospitalier universitaire de Liege

Jean-Baptiste S.Z. Kakoma

Universite de Lubumbashi Faculte de Medecine

Research

Keywords: Obstetric fistula, Socio-demographic, Delivery, Haut-Katanga

Posted Date: March 5th, 2020

DOl: https://doi.org/10.21203/rs.3.rs-16149/v1

License: (9) This work is licensed under a Creative Commons Attribution 4.0 International License.

Read Full License 


\section{Abstract}

Background: In developing countries, fistulae are generally caused by long obstructed labors. Obstetric fistula (OF) is a severe condition which can have devastating consequences for a woman's life.

This study aims to describe the socio-demographic and delivery characteristics of patients with OF in Haut-Katanga province in the Democratic Republic of Congo.

Methods: This is a prospective descriptive study of 413 patients with OF in Haut-Katanga province during the period from September 2009 to December 2018.

Results: At fistula occurrence, $53.3 \%$ of patients were younger than 20 years (mean age: $21.3 \pm 6.7$ years) and $65.8 \%$ were primiparous. More than half had primary education and $39.7 \%$ were illiterate; $70.2 \%$ of the patients were separated or divorced. Fistula developed after delivery at home in $239(57.9 \%)$ of 413 women. A total of 393 (95.2\%) women developed fistula after vaginal delivery. A total of $387(93.7 \%)$ of the 413 women reported that the fetus did not survive the labor during which fistula developed. $92.3 \%$ had a vesico-vaginal fistula and the mean age of fistula was 6.5 years. Surgical repair was successful in $82.9 \%$.

Conclusion: Obstructed labor remains the most important cause of OF in Haut-Katanga. It is important to prevent OF arising from obstructive causes. The surgical treatment of OF will depend upon the type, size and location of fistula.

\section{Plain English Summary}

Obstetric fistula (OF) is an abnormal communication between the vagina and the urological or colorectal systems, caused by obstetrical trauma, which results in an uncontrollable loss of urine or stool. OF is common among women living in low-income countries, where it usually develops as a result of obstructed labor and inadequate access to prenatal and intrapartum care. In this study, we describe the socio-demographic and delivery characteristics of patients with OF in Haut-Katanga province (Democratic Republic of Congo).

This study involved 413 women with OF who came after community awareness in this province during the period from September 2009 to December 2018. The recruitment process consisted of awareness periods by non-governmental organizations working in this domain. They went to the far reaches of the country to look for women with OF.

On the socio-cultural level, this environment is characterized by ethnocultural beliefs that regard as sacred early marriages, home deliveries and delivery by vaginal birth, the latter praised as the method of delivery whatever the cost. Women with OF is often very young, primiparous, low-educated, abandoned by her partner, and had parturition at home assisted by an untrained traditional birth attendant. The OF is often vesico-vaginal and repaired after several years. 
In conclusion, obstructed labor remains the most important cause of OF in Haut-Katanga province. It is important to prevent OF arising from obstructive causes. For the definitive eradication of this devastating disease in our country, national strategies focused on prevention are much more important.

\section{Background}

An obstetric fistula (OF) is an abnormal communication between the vagina and the urological or colorectal systems, caused by obstetrical trauma, which results in an uncontrollable loss of urine or stool [1]. OF is common among women living in low-income countries, where it usually develops as a result of obstructed labor and inadequate access to prenatal and intrapartum care [2]. OF is a global health challenge, although it is difficult to get an accurate count because of the lack of accurate data and statistics, and the fact that OF mainly affects women living in the most remote areas.

About 2 to 3.5 million women live with fistula worldwide, with 50,000-100,000 new cases occurring each year, most of which are in sub-Saharan Africa and Asia [3-6]. The exact prevalence in the Democratic Republic of Congo (DRC) is not well known, but the United Nations Population Fund (UNFPA) estimates that about 40,000 women suffer from OF [3]. The 2007 Demographic and Health Survey indicated that $0.3 \%$ of women report having already experienced fistula symptoms [7]. In fact, these values probably underestimate the true occurrence of obstetric fistula because many of the affected women remain unidentified because of their social isolation. In developing countries, the literature review shows that OF seems to be linked to certain socio-economic and cultural factors such as young age at marriage, poverty and illiteracy, living in rural areas with a lack of obstetric care $[5,8]$.

Obstetric fistula usually affects primiparous who have worked for several days at home, without access to emergency obstetric care, including rescue procedures such as cesarean section [8].

The main objective of this study was to describe the socio-demographic and delivery characteristics of patients with OF in Haut-Katanga province in the DRC.

\section{Methods}

This is a prospective descriptive study that took place from September 2009 to December 2018 in the province of Haut-Katanga (DRC). This work is the result of several campaigns of free surgical obstetric fistula organized by non-governmental organizations (UNFPA, Médecins du Désert, Médecins sans Frontières Hollande) in collaboration with the provincial Ministry of Public Health who wanted to give access to specialized care to the population more specifically that living in the following health zones: Pweto, Kilwa, Mitwaba, Kasenga, Kashobwe and Lubumbashi.

This study involved 413 women with OF who came after community awareness in and around these health zones. We included all women with OF referral for surgical repair during the study period and in our study setting. The data was collected by a questionnaire whose data were collected from the patient's interview, the outpatient registers, the operating room register, and the hospital records. These documents 
provided necessary information on women from admission to discharge. The recruitment process consisted of awareness periods by non-governmental organizations (NGOs) working in this domain. They go to the far reaches of the country to look for women with OF.

We studied the socio-demographic and delivery characteristics of these patients, parameters related to fistula and outcome of surgical repair.

Statistical analyzes were made using the STATA 15 software. We used the whole sample to summarise sociodemographic, obstetrical and fistula characteristics, and the outcome of surgical repair with frequencies (\%) and mean (with standard deviation).

This study obtained the approval of the Medical Ethics Committee of the University of Lubumbashi. The data was collected anonymously.

\section{Results}

A total of 413 patients with OF were enrolled during the study period. At the time of recruitment for surgical repair, the mean age of the patients was $27.8 \pm 9.9$ years and $47.5 \%$ of the patients were aged 20 to 29 years. Patients had a mean parity of $2.4 \pm 2.1$ and almost $50 \%$ were primiparous. More than half had primary education and $39.7 \%$ were illiterate; $70.2 \%$ of the patients were separated or divorced (Table 1). At fistula occurrence, $53.3 \%$ of patients were younger than 20 years (mean age: $21.3 \pm 6.7$ years) and $65.8 \%$ were in their first delivery experience (mean parity: $1.6 \pm 1.0$ ).

Fistula developed after delivery at home in 239 (57.9\%) of 413 women. A total of 393 (95.2\%) women developed fistula after vaginal delivery, while the other 20 (4.8\%) reported having delivered by caesarean section. In more than $30 \%$ of the patients, the labor of delivery lasted 3 days or more (mean duration of labor: 2.2 days). A total of 387 (93.7\%) of the 413 women reported that the fetus did not survive the labor during which fistula developed (Table 2).

The mean age of fistula was 6.5 years and nearly $43 \%$ of fistulas were 5 years or older. Almost $26 \%$ of our sample had a history of fistula repair and $26.2 \%$ had cicatricial fibrosis (Table 3 ).

Of the 413 women, 381 (92.3\%) had a vesico-vaginal fistula, $23(5.6 \%)$ had a recto-vesico-vaginal fistula, $5(1.2 \%)$ a rectovaginal fistula, $2(0.5 \%)$ an uterovaginal fistula and $2(0.5 \%)$ a vesico-uterine fistula. A total of 392 women underwent surgical repair to correct the fistula, and in 325 (82.9\%) of these women, surgical repair was successful (complete closure of the fistula with or without sphincter deficiency). Nearly $79 \%$ (308/392) of the fistulas had been repaired by trans-vaginal approach (Table 3).

\section{Discussion}

This study shows that at the onset of fistula, the mean age was 21.4 years and more than half of the patients were adolescent (<20 years). In Zambia, Holme et al. found that the mean age of patients with 
OF was 22 years old [8]. Obstetric fistula occurs predominantly in young parturient: the very young age of the patient has been noted by several authors [8-10]. Previous studies have found a high rate of obstetrical complications in teenagers $[11,12]$. The increased obstetrical risk in adolescent girls may be partially explained by anatomical immaturity which is responsible for the anomalies of the basin and to more frequent obstetric complications [13].

The majority of our patients (65.8\%) were primiparous at the onset of fistula. Our results are comparable to other studies conducted in Uganda and Zambia where women with OF were primiparous at fistula occurence $[8,14]$. This shows that obstetric fistula usually affects primiparas probably because of pelvic insufficiency leading to prolonged and obstructed deliveries (cephalopelvic disproportion) of up to more than two days on average. These deliveries took place at home in most cases (57.9\%). In other cases, deliveries are carried out in a health facility (health center or reference general hospital) but this does not fully involve the skills of health professionals. Our patients, mostly rural, live in remote areas, isolated with a poor road network, making emergency obstetric evacuation difficult or late. These patients travel hundreds of kilometers to reach a health center where they arrive with obstructed labor and fistula under development. As shown in several previous studies, deliveries producing fistulas occurred at home in 70.7 to $97.1 \%$ [15-18].

The vaginal route was the main route of delivery at the onset of fistula in our study and caesarean section was performed in $4.8 \%$ of cases. Diverging results in Zambia and West Africa $[2,8,19]$ have been reported with $50 \%$ of fistulas occurring during caesarean section.

Regarding the neonatal outcome during fistula delivery, perinatal mortality was $93.7 \%$ in our study, ranging from 78.1 to $96 \%$ in the literature $[8,20,21]$. This excess neonatal mortality is easily understood if one considers the duration of the labor, which is generally long, which can reach several days, and fistula's development is only the result of the body's struggle against dystocia. Nsambi et al. highlight the more frequent use of particularly harmful practices during deliveries conducted at home: traditional birth attendants make use of prohibited maneuvers (e.g. use of mortar and pestle pressure on the belly of the parturient) to force the expulsion of the fetus, thus leading to obstetric morbidities such as uterine rupture or obstetric fistula [15]. This situation points to delays in access to emergency obstetric care and the like in all studies that have been conducted in low-resource countries. Reasons for the delayed decision to seek care may include financial, cultural, religious and geographic reasons, with many women living too far from a clinic to receive timely care $[15,16]$.

One hundred and twenty-three (29.8\%) patients in our study were living with their husband despite fistula, and these results appear to be lower than those observed in Zambia [8], where $75.7 \%$ of fistula patients were still married. This differs from our results and previous studies that seemed to suggest that women with obstetric fistula were neglected and abandoned by their husbands $[5,6]$. This difference in the proportion of married women is difficult to explain, but perhaps because of differences in culture and religious beliefs in different studies. 
A high number of our patients in this study had a very low level of education (only $5.3 \%$ had a secondary level). This could be explained by the fact that women with obstetric fistula had dropped out of school to get married or had an early pregnancy. The same is true of other authors who reported a high number of patients without formal education $[2,5,15,22]$. This could be explained by the low literacy rate in rural areas where these women live [7].

The majority of patients in our study (92.3\%) had a vesico-vaginal fistula alone and 28 patients (6.8\%) had a rectovaginal fistula alone or associated with a vesico-vaginal. Our results corroborate those of previous studies where most patients had vesico-vaginal fistula $[8,14,15]$. This high frequency of vesicovaginal fistulas compared to other fistulas is probably due to the greater likelihood of compression of the anterior vaginal wall by the fetal head against the pelvis resulting in more ischemia of the bladder than the rectum.

The success rate after surgical repair of the fistula varies from one center to another and is determined by many factors such as the fistula site, the degree of healing, previous attempts at repair, the technique of surgical repair, and the expertise of the surgeon, equipment, and post-operative nursing. The success rate in our study was $82.9 \%$. Such high success rates after repair are reported by other authors ranging from 72.9 to $93 \%[8,15,23-25]$. But even after successful closure $15-20 \%$ of cases may continue to suffer from urinary incontinence related to sphincter deficiency and not to leakage to the fistula site. Closing the bladder is much more important in achieving a successful repair than vaginal closure. As long as these principles are respected, the surgical approach often concludes successfully. In most cases, the choice is essentially dictated by the procedure with which the surgeon is more comfortable and familiar.

In our series, $79 \%$ of cases were repaired trans-vaginally. We have personally favored the vaginal approach when the fistula is near the neck of the bladder. The benefits include a low rate of complications, minimal bleeding, rapid postoperative recovery and short hospital stay [26]. We reserved the trans-vesical approach when the fistula could not be correctly visualized (upper fistula located) and when an intra-abdominal disease state requires simultaneous care.

\section{Conclusion}

The obstructed labor remains the most important cause of OF in Haut-Katanga. It is important to prevent OF arising from obstructive causes. The surgical treatment of OF will depend upon the type, size and location of fistula. Prevention is based on proper monitoring of pregnancies and delivery in a medical facility. This information could potentially be used to educate rural populations in DRC, guide public policies and improve morbidity and mortality among Congolese women and their children.

\section{Abbreviations}

DRC

Democratic Republic of Congo 
NGO

non-governmental organizations

OF

obstetric fistula

\section{Declarations}

\section{Ethics approval and consent to participate}

The approval to conduct the study and authorizations were obtained from the Medical Ethic Committee of the University of Lubumbashi ((NUNILU/CEM/101/2018). Data was used with high confidentiality and no names were recorded.

\section{Consent for publication}

The approval to publish the study was obtained from all patients.

\section{Availability of data and material}

Raw data and other relevant materials are available upon request from the corresponding author (OM).

\section{Competing interests}

The authors declare that no conflict of interest is linked to the study.

\section{Funding}

We have not received any funding. The study was conducted on our own.

\section{Authors' contributions}

JBN, OM and JBK carried out the conceptualization, design, data collection and analysis for the study. JBN, PLK, RA and JBK contributed to the interpretation of the findings and the drafting of the article. JBN and $\mathrm{OM}$ wrote the manuscript. All authors read and approved the final manuscript.

\section{References}

1. Langkilde NC, Pless TK, Lundbeck F, Nerstrøm B. Surgical repair of vesicovaginal fistulae-a ten-year retrospective study. Scand J Urol Nephrol 1999;33(2):100-3.

2. Wall LL, Karshima JA, Kirschner C, Arrowsmith SD. The obstetric vesicovaginal fistula: characteristics of 899 patients from Jos, Nigeria. Am J Obstet Gynecol 2004; 190(4):1011-9.

3. Campaign to end fistula. 2008. Accessible sur http://www.endfistula.org et consulté le 27 juillet 2017. 
4. Creanga AA, Ahmad S. Prevention and treatment of Obstetric fistula: Identifying research needs and public health priorities. International Journal of Gynaecology and Obstetrics 2007; 99(1): 151-4.

5. Muleta M. Socio-demographic Profile and Obstetric experience of fistula Patients managed at Addis Ababa fistula hospital. Ethiopia Medical Journal 2004; 42(1):9-16.

6. Wall LL. Obstetric Vesicovaginal fistula as an International Public Health problem. The Lancet 2006, 368(9542):1201-1209.

7. Ministère du Plan et Macro International. 2008. Enquête Démographique et de Santé, République Démocratique du Congo 2007. Calverton, Maryland, U.S.A. : Ministère du Plan et Macro International.

8. Holme A, Breen M, MacArthur C. Obstetric fistulae: a study of women managed at the Monze Mission Hospital, Zambia. BJOG 2007; 114(8): 1010-1017.

9. Harouna YD, Seibou A, Maikano S, Djambeidou J, Sangare A, Bilane SS, Abdou HM. Enquêtes auprès de 52 femmes admises au village des fistuleuses. Niamey, Niger. Médecine d'Afrique Noire 2001; 48 (2) : 55-59.

10. Falandry L. Vesicovaginal fistula in Africa. 230 cases. Presse Med 1992; 21(6):241-245.

11. Ayuba II, Gani O. Outcome of teenage pregnancy in the Niger delta of Nigeria. Ethiop J Health Sci. 2012; 22 (1): 45-50.

12. Tebeu PM, Tantchou J, Obama Abena MT, Mevoula OD, Leke RJ. Delivery outcome of adolescents in Far North Cameroon. Rev Med Liege 2006; 61(2):124-127.

13. Kakudji PL, Mukuku O, Tambwe AM, Kalenga PM. Etude du pronostic maternel et périnatal au cours de l'accouchement chez l'adolescente à Lubumbashi, République Démocratique du Congo. The Pan African Medical Journal 2017; 26: 182.

14. Hancock B, Collie M. Vesicovaginal fistula surgery in Uganda. East and Central African Journal of surgery 2004; 2:95-99.

15. Nsambi JB, Mukuku O, Kinenkinda X, Kakudji P, Kizonde J, Kakoma JB. Fistules obstétricales dans la province du Haut-Katanga, République Démocratique du Congo: à propos de 242 cas. Pan African Medical Journal 2018; 29: 34.

16. Meyer L. Commonalities among women who experienced vesico-vaginal fistula as a result of obstetric trauma in Niger: results from a survey given at the National Hospital Fistula Centre, Niamey Niger. Am J Obstet Gynecol 2007; 197: 90.e1-4.

17. Ijaiya MA, Aboyeji PA. Obstetric urogenital fistula: the llorin experience, Nigeria. West Afr J Med 2004; 23(1):7-9.

18. Hilton P, Ward A. Epidemiological and surgical aspects of urogenital fistulae: a review of 25 years' experience in southeast Nigeria. Int Urogynecol J Pelvic Floor Dysfunct 1998; 9:189-94.

19. Nathan LM, Rochat HC, Bank E, Gringorescu B. Obstetric fistula in West Africa: patients' perspectives. Am J Obstet Gynecol 2008; 200(5):40-42.

20. Nafiou I, Idrissa A, Ghaïchatou AK, Roenneburg ML, Wheeless CR, Genadry RR. Obstetric vesicovaginal fistulas at the National Hospital of Niamey, Niger. International Journal of Gynecology and 
Obstetrics 2007; 99: S71-S74.

21. Rijken Y, Chilopora GC. Urogenital and recto-vaginal fistulas in southern Malawi: a report on 407 patients. Int J Gynaecol Obstet 2007; 99(Suppl 1):S85-S89.

22. Nisar N, Yousfani S, Muntaz F: Profile of women who experienced vesicovaginal fistula due to obstetric trauma: results from a survey at a gynaecological surgical camp 2005. Pak J Med Sci $2010 ; 26(1): 62-65$.

23. Muleta M. Obstetric fistula: a retrospective study of 1210 cases at the Addis Ababa Fistula Hospital. J Obstet Gynaecol 1997; 17:68-70.

24. Kambou T, Zango B, Outtara TA, Dao B, Sano D. Point sur la prise en charge des fistules uro-génitales au CHU Souro Sanou de Bobo-Dioulasso : étude de 57 cas opérés en deux ans. Médecine d'Afrique Noire 2006; 53 (12): 665-673.

25. Moudouni S, Nouri M, Koutani A, Ibn Attya A, Hachimi M, Lakrissa A. Les fistules vésico-vaginales obstétricales. A propos de 114 cas. Progrès en Urologie 2001 ; 11: 103-108.

26. Kayondo $\mathrm{M}$, et al. Predictors and outcome of surgical repair of obstetric fistula at a regional referral hospital, Mbarara, western Uganda. BMC Urology 2011; 11:23.

\section{Tables}

Table 1: Socio-demographic characteristics of patients with OF at surgical repair

\begin{tabular}{ccc}
\hline \multicolumn{1}{l}{ Variable } & $\begin{array}{c}\text { Number } \\
\text { Age }\end{array}$ & \\
<20 years & $76)$ & Percentage \\
\hline 20-29 years & 196 & 47.5 \\
\hline 30-39 years & 93 & 22.5 \\
\hline$\geq 40$ years & 48 & 11.6 \\
\hline Parity & & \\
\hline 2-4 & 205 & 49.6 \\
\hline$\geq 5$ & 145 & 35.1 \\
\hline Nudcation level & 63 & 15.3 \\
\hline Primairy & 227 & 55.0 \\
\hline Secondary & 22 & 5.3 \\
\hline Marital status & & \\
\hline Divorced/Separated & 290 & 70.2 \\
\hline Married/Union & 123 & 29.8 \\
\hline
\end{tabular}

Table 2: Socio-demographic and delivery characteristics of patients with OF at the onset of obstetric fistula 


\begin{tabular}{|c|c|c|}
\hline Variable & $\begin{array}{l}\text { Number } \\
(\mathrm{n}=413)\end{array}$ & Percentage \\
\hline \multicolumn{3}{|l|}{ Age at onset of fistula } \\
\hline$<20$ years & 220 & 53.3 \\
\hline 20-29 years & 149 & 36.1 \\
\hline$\geq 30$ years & 44 & 10.6 \\
\hline \multicolumn{3}{|l|}{ Parity at onset of fistula } \\
\hline 1 & 272 & 65.8 \\
\hline 2 & 87 & 21.1 \\
\hline$\geq 3$ & 54 & 13.1 \\
\hline \multicolumn{3}{|l|}{ Event after which fistula occurred } \\
\hline Vaginal delivery & 393 & 95.2 \\
\hline Cesarean section & 20 & 4.8 \\
\hline \multicolumn{3}{|l|}{ Duration of labor } \\
\hline 1 day & 55 & 13.3 \\
\hline 2 days & 232 & 56.2 \\
\hline$\geq 3$ days & 126 & 30.5 \\
\hline \multicolumn{3}{|l|}{ Place of delivery } \\
\hline Home & 239 & 57.9 \\
\hline Health center & 91 & 22.0 \\
\hline Reference general hospital & 83 & 20.1 \\
\hline \multicolumn{3}{|l|}{ Neonatal outcome at delivery } \\
\hline Stillborn & 387 & 93.7 \\
\hline Alive & 26 & 6.3 \\
\hline
\end{tabular}

Table 3: Fistula's characteristics and outcome of surgical repair 


\begin{tabular}{|c|c|c|}
\hline Variable & $\begin{array}{l}\text { Number } \\
(\mathrm{n}=413)\end{array}$ & Percentage \\
\hline \multicolumn{3}{|l|}{ Age of fistula } \\
\hline$<1$ year & 7 & 1.7 \\
\hline $1-4$ years & 229 & 55.4 \\
\hline$\geq 5$ years & 177 & 42.9 \\
\hline \multicolumn{3}{|l|}{ Previous surgical repair } \\
\hline None & 306 & 74.1 \\
\hline One & 67 & 16.2 \\
\hline Two or more & 40 & 9.7 \\
\hline \multicolumn{3}{|l|}{ Vaginal scarring } \\
\hline Yes & 108 & 26.2 \\
\hline No & 305 & 73.8 \\
\hline \multicolumn{3}{|l|}{ Type of fistula } \\
\hline Vesico-vaginal & 381 & 92.3 \\
\hline Rectovesico-vaginal & 23 & 5.6 \\
\hline Rectovaginal & 5 & 1.2 \\
\hline Uretero-vaginal & 2 & 0.5 \\
\hline Vesico-utérine & 2 & 0.5 \\
\hline \multicolumn{3}{|l|}{ Number of fistula } \\
\hline 1 & 375 & 90.8 \\
\hline 2 & 35 & 8.5 \\
\hline 3 & 3 & 0.7 \\
\hline \multicolumn{3}{|l|}{ Route of repair* } \\
\hline Vaginal & 308 & 78.6 \\
\hline Abdominal & 71 & 18.1 \\
\hline Combined & 13 & 3.3 \\
\hline \multicolumn{3}{|c|}{ Outcome of surgical repair } \\
\hline Success & 325 & 78.7 \\
\hline Failure & 67 & 16.2 \\
\hline No operated & 21 & 5.1 \\
\hline
\end{tabular}

$*_{n}=392$ 